\title{
Cadherin 8 regulates proliferation of cortical interneuron progenitors
}

\author{
Fani Memi ${ }^{1} \cdot$ Abigail C. Killen $^{1} \cdot$ Melissa Barber $^{1} \cdot$ John G. Parnavelas ${ }^{1} \cdot$ William D. Andrews $^{1}$ (i)
}

Received: 24 April 2018 / Accepted: 5 October 2018 / Published online: 12 October 2018

(c) The Author(s) 2018

\begin{abstract}
Cortical interneurons are born in the ventral forebrain and migrate tangentially in two streams at the levels of the intermediate zone (IZ) and the pre-plate/marginal zone to the developing cortex where they switch to radial migration before settling in their final positions in the cortical plate. In a previous attempt to identify the molecules that regulate stream specification, we performed transcriptomic analysis of GFP-labelled interneurons taken from the two migratory streams during corticogenesis. A number of cadherins were found to be expressed differentially, with Cadherin-8 (Cdh8) selectively present in the IZ stream. We verified this expression pattern at the mRNA and protein levels on tissue sections and found approximately half of the interneurons of the IZ expressed Cdh8. Furthermore, this cadherin was also detected in the germinal zones of the subpallium, suggesting that it might be involved not only in the migration of interneurons but also in their generation. Quantitative analysis of cortical interneurons in animals lacking the cadherin at E18.5 revealed a significant increase in their numbers. Subsequent functional in vitro experiments showed that blocking Cdh8 function led to increased cell proliferation, with the opposite results observed with over-expression, supporting its role in interneuron generation.
\end{abstract}

Keywords Cell migration $\cdot$ Cadherin $\cdot$ Interneurons $\cdot$ Proliferation

\section{Introduction}

Interneurons constitute a morphologically, neurochemically and functionally diverse group of cortical neurons that are essential modulators of neuronal activity in the cerebral cortex. Abundant evidence indicates that alterations in the number, distribution and function of these GABA-releasing inhibitory neurons in humans may lead to neurological and psychiatric disorders, including some of developmental origin (Benes and Berretta 2001; Cossart et al. 2005; Gant et al. 2009). Thus, a great deal of effort has been devoted to understanding the mechanisms that control their development.

Whilst many molecules have been identified as regulators of interneuron migration (Faux et al. 2012; Marin 2013; Guo and Anton 2014), little is known about the factors that determine their choice of tangential migratory stream as they enter the cortex. Previously, we reasoned that molecular/

John G. Parnavelas

j.parnavelas@ucl.ac.uk

$\triangle$ William D. Andrews

w.andrews@ucl.ac.uk

1 Department of Cell and Developmental Biology, University College London, Gower Street, London WC1E 6BT, UK genetic differences between interneurons underlie their choice of one of the two early tangential pathways. To identify genes involved in migratory stream specification, we previously compared the gene expression profiles of cells in the pre-plate (PPL) zone with those of cells migrating through the IZ during early corticogenesis (E13.5). Our analysis identified several cadherin family members that showed differential expression, including $\mathrm{Cdh} 8$, which was present only in the IZ at this stage (Antypa et al. 2011), a finding recently supported by another study (Pensold and Zimmer 2018).

Cdh 8 is a classical type II cadherin that can bind $\beta$-catenin (Kido et al. 1998). Whilst many type-II cadherins are expressed rather ubiquitously during CNS development, there are a few amongst their number that exhibit restricted expression patterns that are spatially and temporally regulated (Lefkovics et al. 2012). Most studies examined Cdh8 expression perinatally and postnatally, when it is expressed strongly in certain layers of the cortex, hippocampus and striatum (Korematsu and Redies 1997a, b; Korematsu et al. 1998b; Medina et al. 2004; Lefkovics et al. 2012). Differential expression of Cdh8 within the striatum has been suggested to aid segregation and aggregation of cell types (Korematsu et al. 1998a). Cdh8 has also been found to have 
a role in the migration and growth of other neuronal cell types (Garel et al. 2000; Taniguchi et al. 2006; Bekirov et al. 2008), and to have a function in the establishment and remodelling of synapses and in coupling between neurons (Suzuki et al. 2007; Bekirov et al. 2008; Huntley et al. 2012). On the basis of these findings, we postulated that $\mathrm{Cdh} 8$ could have many roles in interneuron development.

Here we carried out a detailed expression analysis of Cdh8 throughout the whole period of corticogenesis and analysed the interneuron phenotype in Cdh8 knockout animals. We observed differences in the number of interneurons in these mice and assessed the roles of Cdh8 in cell migration, apoptosis and proliferation. Our findings identified a novel function for this cadherin in cortical interneuron development.

\section{Materials and methods}

\section{Animals}

All experimental procedures were performed in accordance with the UK Animals (Scientific Procedures) Act 1986 and institutional guidelines. Wild-type animals were C57/bl6J mice obtained from Charles River Ltd. $C d h 8^{-/-}$knockout (KO) mice and GAD67-GFP $P^{\text {neol- }}$ mice were generated as described previously (Tamamaki et al. 2003; Suzuki et al. 2007). The day the vaginal plug was found was considered as embryonic day (E) 0.5. Animals of both sexes were used in our experiments.

\section{Cell lines}

COS-7 cells (American Type Culture Collection) and GN11 cells were grown as monolayers at $37^{\circ} \mathrm{C}$ in a humidified $\mathrm{CO}_{2}$ incubator in DMEM (ThermoFisher Scientific) and supplemented with $10 \%$ foetal bovine serum (FBS) (ThermoFisher Scientific) and $100 \mathrm{U} / \mathrm{ml}$ penicillin/streptomycin (Gibco). Subconfluent cells were harvested by trypsinization and cultured in $10 \mathrm{~cm}^{2}$ dishes. Media was changed to low-serum Optimem (Gibco) $24 \mathrm{~h}$ prior to collection of conditioned media for Western blot and chemotaxis migration assays. Cells within six passages were used in all experiments.

\section{In situ hybridization}

For in situ hybridization and immunohistochemistry, embryonic brains were dissected in PBS and fixed in 4\% paraformaldehyde (PFA), made in phosphate buffered saline (PBS), for 4-8 $\mathrm{h}$ at room temperature (RT). Following fixation, embryonic brains were cryoprotected in $30 \%$ sucrose in diethyl pyrocarbonate (DEPC) treated PBS, embedded and frozen in a mixture of $15 \%$ sucrose $/ 50 \%$ Tissue-Tek
OCT (Sakura Finetek), and sectioned in the coronal plane at $20 \mu \mathrm{m}$ using a Cryostat (Bright Instruments). Sections were dried at RT for $2 \mathrm{~h}$ before overnight incubation at $65{ }^{\circ} \mathrm{C}$ in hybridization buffer $[1 \times$ DEPC treated 'Salts' (200 mM NaCl, $5 \mathrm{mM}$ EDTA, $10 \mathrm{mM}$ Tris pH 7.5, $5 \mathrm{mM}$ $\mathrm{NaH}_{2} \mathrm{PO}_{4} \cdot 2 \mathrm{H}_{2} \mathrm{O}, 5 \mathrm{mM} \mathrm{Na}{ }_{2} \mathrm{HPO} 4$; Merck); $50 \%$ deionized formamide (Ambion); $0.1 \mathrm{mg} / \mathrm{ml}$ RNAse-free yeast tRNA (ThermoFisher Scientific); $1 \times$ Denhardts (RNase/DNase free; ThermoFisher Scientific); $10 \%$ dextran-sulphate (Merck)] containing 100-500 ng/ml DIG labelled-RNA probes. Probes were generated by linearization of plasmids with appropriate enzymes and reverse transcription polymerases to obtain antisense probes. $C d h 8$ and $L h x 6$ probes were kindly provided by Prof. Gregor Eichele (Max Planck Institute for Biophysical Chemistry, Göttingen, Germany). Following hybridization, sections were washed 3 times in 50\% formamide 1XSSC (Ambion) and 0.1\% Tween-20 (Merck) at $65{ }^{\circ} \mathrm{C}$ and two times at RT in $1 \mathrm{XMABT}$ ( $20 \mathrm{mM}$ Maleic acid, $30 \mathrm{mM} \mathrm{NaCl}, 0.1 \%$ Tween-20; Merck) before incubating in blocking solution [2\% blocking reagent (Roche), $10 \%$ normal goat serum (Vector Laboratories) in MABT] followed by overnight incubation in alkaline phosphatase conjugated anti-DIG antibody (1:1500; Roche). Nitro blue tetrazolium chloride/5-bromo-4-chloro-3-indolyl phosphate (Roche) diluted 1:1000 in MABT with 5\% polyvinyl alcohol (VWR International Ltd) was used for the colorimetric detection for $6 \mathrm{~h}$. Fast Red (Roche) was used for fluorescent colour detection of probes by incubation in $100 \mathrm{mM}$ Tris (pH 8.0) and $400 \mathrm{mM} \mathrm{NaCl}$ containing Fast Red at $37^{\circ} \mathrm{C}$ for approximately $2 \mathrm{~h}$. Fluorescent in situ hybridization was followed by immunohistochemical detection of GFP as described below. Sections were mounted with Glycergel Mounting Medium (Dako).

\section{Immunohistochemistry}

Embryonic brain sections were washed in PBS, blocked in a solution of 5\% normal goat serum (Merck) (v/v) containing $0.1 \%$ Triton X-100 (v/v) (Merck) in PBS at RT for $2 \mathrm{~h}$. They were subsequently incubated in primary antibodies at RT for $2 \mathrm{~h}$ and then at $4{ }^{\circ} \mathrm{C}$ overnight. The following antibodies were used: mouse monoclonal Nestin (1:100, DSHB) and 5-Bromodeoxyuridine (BrdU; 1:1000, Progen), Cad8-1 (1:100, DSHB), chicken polyclonal raised against GFP (1:500, Aves Laboratories), rabbit polyclonal raised against calbindin (CB-28; 1:3000, Swant), cleaved caspase-3 (CC3; 1:250, Cell Signaling Technology), Ki67 (1:1000, Cell Signaling), Tbr2 (1:500, Abcam) or phosphohistone H-3 (PH-3; 1:1000, Millipore). For blood vessel staining, sections were incubated with biotinylated Griffonia (Bandeiraea) Simplicifolia lectin I (Isolectin B4) (1:200, Vector) followed by fluorescent Strepatividin-405 (1:200, Vector Laboratories). 


\section{Interneuron counts}

In Cdh8 knockout sections at E18.5, $300 \mu \mathrm{m}$ was measured along the ventricular surface of the cortex next to the cortico-striatal junction. A rectangle was then drawn to incorporate the entire thickness of the cortex within the $300 \mu \mathrm{m}$, and the number of stained cells in that area was counted. We quantified the number of interneurons in each layer of the cortex as well as the total number.

\section{Plasmids and RNAi constructs}

For over-expression experiments, we first generated mouse cDNA from E13.5 mouse forebrain mRNA obtained using RNAeasy kit (Qiagen), and Superscript III cDNA synthesis kit (Invitrogen). Mouse $C d h 8$ cDNA was produced by PCR amplified using $P f u$ polymerase (Promega) (Forward (NheI), GCTAGCGATGCCAGAAAGGCTTGCTGAGACGC; Reverse (KpnI), CCACTTTCACTGTTTCTTTGACCATGG TTC), digested with NheI and HindIII and subcloned into the pCDNA3.1 (-) expression vector (Promega). For RNAi experiments, we designed four different oligonucleotides; targeting specific regions of mouse $C d h 8 \mathrm{cDNA}$ (GenBank accession number NM_007667.3), S1 specifically recognizes nucleotides 903-921, GCTGGCACAATCTTTCAAA; S2, nucleotides 1554-1569, GCACTATTCGAAATCA; S3, nucleotides 1917-1935, GCAGATGATGGGAAGATAA; S4, nucleotides 2078-2097, GCGCATCCGAATATGAGG CAT; S1m, nucleotides GCTGGCAGTATCT $\underline{\text { ATCAAA, }}$ nucleotides highlighted in bold and underlined were altered from sequence $\mathrm{S} 1$.

Annealed oligonucleotides were cloned in the GeneClip ${ }^{\mathrm{TM}}$ U1 Hairpin-hMGFP vector according to the manufacturer's instructions (Promega). As controls, we used short interfering RNAs (siRNAs) targeting the same regions, but containing three-point mutations and, thus, not affecting the stability of $C d h 8$ mRNA. The efficiency of the different siRNAs in targeting $C d h 8$ mRNA was determined by cotransfecting mouse $C d h 8$ cDNA and the different siRNAs at a ratio 1:3, using Lipofectamine 2000 (Invitrogen), into COS-7 cells. After $48 \mathrm{~h}$, mRNA and protein were harvested and the level of knockdown determined.

\section{qPCR}

cDNA from transfected and MGE cells was analysed by qPCR. The qPCR reaction was performed with SYBR Green reagent (Sigma) on a CFX96 ${ }^{\mathrm{TM}}$ Real-Time PCR Detector system (Bio-Rad) in accordance with the manufacturer's instructions. Primers for quantitative realtime PCR (QPCR) were designed by Sigma-Genosys and were as follows: $\beta$-Actin (forward, GGCTGTATTCCCCTCCATCG; reverse, CCAGTTGGTAACAATGCCATGT);
$C d h 8$ (forward, TGCATGAGGCAGATA ATG ACCC; reverse, TCTGGTCTGAGTCTGATGTGG); Ccdl(forward GCGTACCCTGACACCAATCTC; reverse CTCCTCTTCGCACTT-CTGTC); Gadl (forward CAC AGGTCACCCTCGATTTTT; reverse ACCATCCAA CGAT-CTCTCTCATC); Gapdh (forward AGGGCA TCTTGGGCTACAC; reverse CATACCAGG-AAATGA CGTTGA); Ki67 (forward ATCATTGACCGCTCCTTT AGGT; reverse GCTCGCCTTGATGGTTCCT); Sox2 (forward CGGCACAGATGCAACCGAT; reverse CCG TTCATGTAGGTCTGCG); GAPDH and $\beta$-actin were used for endogenous reference gene controls. Each primer set amplified a single PCR product of predicted size as determined by melt-curve analysis following PCR and by agarose gel electrophoresis and had approximately equal amplification efficiencies when validated with a serial dilution of representative cDNA. Each qPCR was performed in triplicate, and relative quantification was determined according to the DDc(t) method (Livak and Schmittgen 2001; Faux et al. 2010).

\section{Expression of Cdh8}

COS-7 cells were lysed in lysis buffer $(50 \mathrm{mM}$ Tris- $\mathrm{HCl}$ pH 7.4, $150 \mathrm{mM} \mathrm{NaCl}, 1 \%$ Nonidet P40). The lysate was incubated at $4{ }^{\circ} \mathrm{C}$ for $30 \mathrm{~min}$ and centrifuged for $5 \mathrm{~min}$. Cell lysates were processed for conventional SDS-PAGE and membrane transfer. To assess the protein levels of $\mathrm{Cdh} 8$ and Gapdh, membranes were incubated with the following polyclonal antibodies: goat anti-Cdh8 (1:1000; Santa Cruz), and Gapdh (1:500; Sigma-Aldrich), in 5\% BSA-TBST, washed several times with TBST, and incubated with a horseradish peroxidase-conjugated secondary antibody (1:5000; Vector Laboratories). After intensive washing, the proteins were visualized with ECL detection reagent (GE Healthcare).

\section{Dissociated MGE cell cultures}

Dissociated cell cultures were prepared from embryonic rodents as described previously (Cavanagh et al. 1997). Briefly, MGEs were dissected out in cold artificial CSF (ACSF) under a stereo microscope. They were incubated in trypsinization medium [0.05\% trypsin (Merck) with $100 \mu \mathrm{g} / \mathrm{ml}$ DNaseI (Roche) in neurobasal medium (ThermoFisher Scientific)] at $37{ }^{\circ} \mathrm{C}$ for $15 \mathrm{~min}$. Trypsinization was quenched with neutralization medium (10\% of FBS, ThermoFisher Scientific, in neurobasal medium) at $37{ }^{\circ} \mathrm{C}$ for $5 \mathrm{~min}$. MGEs were then triturated by pipetting until no cellular aggregates were visible. The homogenous cell suspensions were subsequently pelleted by centrifugation at $1000 \times g$ for $3 \mathrm{~min}$. Cells were resuspended in dissociated culture medium (DM) [DMEM/F12 media containing $10 \%$ of FBS and B27 supplement (ThermoFisher Scientific), 
$100 \mu \mathrm{g} / \mathrm{ml}$ penicillin/streptomycin (ThermoFisher Scientific), and $2 \mathrm{mM}$ L-glutamine (ThermoFisher Scientific)] and $1,000,000$ cells were seeded on to $13 \mathrm{~mm}$ coverslips coated previously with $10 \mu \mathrm{g} / \mathrm{ml}$ poly-L-lysine and $10 \mu \mathrm{g} / \mathrm{ml}$ laminin and incubated in a humidified incubator at $37{ }^{\circ} \mathrm{C}$. The culture medium was changed the next day.

\section{Chemotaxis assays}

Chemotaxis assays were performed using a 48-well Boyden's chamber (NeuroProbe) as described previously (Killen et al. 2017). Briefly, $27 \mu \mathrm{l}$ of DM containing $10 \%$ FBS were placed into the lower compartment of the chamber. Dissociated MGE or GN11 cells were re-suspended in serum-free medium $\left(10^{5}\right.$ cells $\left./ 50 \mu \mathrm{l}\right)$ and placed in wells of the upper compartment of the chamber. These were separated from the lower chamber by a polycarbonate porous membrane ( $8 \mu \mathrm{m}$ pores), pre-coated with gelatin $(0.2 \mathrm{mg} / \mathrm{ml})$ for GN11 cells and laminin $(10 \mu \mathrm{g} / \mathrm{ml})$ for MGE cells. The chamber was kept in an incubator at $37{ }^{\circ} \mathrm{C}$ for $4 \mathrm{~h}$ (GN11 cells) or overnight (MGE cells). After incubation, the migrated cells that adhered to the underside of the membrane were fixed and stained using the Diff-Quick kit (Reagena). For quantitative analysis, the membranes were observed using an Olympus light microscope with a $20 \times$ objective adapted with a $500 \times 500 \mu \mathrm{m}$ grid. Four random fields of stained cells were counted for each well, and the mean number of migrating cells per square millimeter for each experimental condition was estimated.

\section{Proliferation/apoptosis experiments}

For apoptosis experiments, $24 \mathrm{~h}$ following transfection of cells with over-expression and knockdown constructs, media was changed to DMEM (ThermoFisher Scientific) without FBS. Next day cells were washed, fixed with $4 \%$ PFA, immunostained for PH3 and Nestin to identify progenitors, and EGFP to identify transfected cells. For analysis of apoptosis in these cultures, $\mathrm{CC} 3$ and calbindin immunohistochemistry was carried out instead of PH3. The percentage of transfected cells immunoreactive for Nestin and $\mathrm{PH} 3$, or calbindin and $\mathrm{CC} 3$, was counted using a $40 \times$ objective lens in nine fields of view for each sample. At least three samples were evaluated for each time point and treatment. For overexpression constructs, the control was cells that had been transfected with empty pcDNA3.1 (ThermoFisher Scientific) vector. For knockdown constructs, the controls were cells that had been transfected with mutated siRNA constructs in the same pGeneClip ${ }^{\mathrm{TM}} \mathrm{hMGFP}$ vector.

\section{BrdU experiment}

BrdU was added to culture medium at a final concentration of $3 \mu \mathrm{g} / \mathrm{ml}$ for $2 \mathrm{~h}$ and cells or slices were fixed for 30 or $60 \mathrm{~min}$ at $4{ }^{\circ} \mathrm{C}$, respectively, with $4 \%$ PFA. They were then washed three times with PBS and treated in $2 \mathrm{~N} \mathrm{HCl}$ for $30 \mathrm{~min}$. After $3 \times$ washes, cells or slices were processed for anti-BrdU immunostaining. Cell cycle length was calculated as the ratio of $\mathrm{BrdU}^{+} \mathrm{Ki} 67^{+} / \mathrm{Ki} 67^{+}$and exit from the cell cycle as the ratio of $\mathrm{BrdU}^{+} \mathrm{Ki}^{-} 7^{-} / \mathrm{BrdU}^{+}$in $\mathrm{MGE}$ cell cultures.

\section{Brain slices}

Brains slices were obtained with Vibratome (Leica VT1000s) and cultured as described previously (Andrews et al. 2013). Briefly, medial coronal brain slices, obtained from E13.5 mice were placed onto nitrocellulose filters $(0.45 \mu \mathrm{m}$; Millipore $)$ in culture medium containing DMEM:F12 (Sigma,-Aldrich), 5\% foetal bovine serum, $1 \times \mathrm{N}-2,1 \times \mathrm{B}-27,100 \mu \mathrm{M}$ L-glutamine, $2.4 \mathrm{~g} / \mathrm{l} \mathrm{D}$-glucose (Sigma-Aldrich), $5 \mathrm{U} / \mathrm{ml}$ penicillin, and $5 \mathrm{mg} / \mathrm{ml}$ streptomycin in a humidified $5 \% \mathrm{CO}_{2}$ incubator at $37{ }^{\circ} \mathrm{C}$ in the presence of $1 \mu \mathrm{g} / \mathrm{ml}$ human IgG (Merck) or $1 \mu \mathrm{g} / \mathrm{ml} \mathrm{Cdh} 8-\mathrm{Fc}$ (R\&D Systems). $24 \mathrm{~h}$ later, they were fixed with $4 \%$ PFA in $0.1 \mathrm{M}$ phosphate buffer, $\mathrm{pH} 7.4$, at $4{ }^{\circ} \mathrm{C}$ for $1 \mathrm{~h}$, before carrying out immunohistochemistry for Ki67 and pH3. Slices were mounted on slides using Mowiol 4-88 and imaged with SP8 confocal microscope (Leica Microsystems). Images were taken at the level of MGE, and Photoshop CS6 was used for cell quantification. A box of $10^{4} \mu \mathrm{m}^{2}$ surface was drawn at the VZ or SVZ and the number of stained cells in that box was counted.

\section{Digital image acquisition and processing}

Optical and fluorescent images were collected using a Leica Microsystems light microscope (DM5000B), and with the SP8 confocal microscope (Leica Microsystems). Images were reconstructed and digitized with Photoshop CS6 software (Adobe Systems).

\section{Statistics}

Statistical analyses were performed by GraphPad 3 (GraphPad Software). All data are reported as mean number and SEM. The statistical significance between group means was tested by one-way ANOVA, followed by Bonferroni's post hoc test (for multiple comparison tests) or Student's $t$ test for paired comparisons. Significance was set at $p \leq 0.05$. 


\section{Results}

We previously carried out a microarray analysis to identify genes that showed differential expression between the early tangential migratory streams, which may underlie the choice of pathway for migrating cortical interneurons (Antypa et al. 2011). This analysis identified several differentially expressed cadherin molecules, including Cdh8, which appeared to be expressed specifically in the IZ during early corticogenesis (E13.5). Previous studies have given a fairly detailed account of $C d h 8$ expression perinatally and, especially, postnatally in the developing rodent brain (Korematsu and Redies 1997a, b; Korematsu et al. 1998b; Medina et al. 2004; Lefkovics et al. 2012), but little is known about its expression in the early-mid developing cortex. We, therefore, undertook a detailed analysis of $C d h 8$ expression in the embryonic mouse telencephalon, focusing on its relation to the development of cortical interneurons. This was achieved by in situ hybridization and immunohistochemistry in coronal cryosections of mouse telencephalon at early (E13.5), middle (E15.5) and late (E18.5) stages of embryonic cortical development.

At E13.5, there is a distinct pattern of $C d h 8$ mRNA expression in cells of the IZ in rostral, medial and caudal cortical regions (Fig. 1a-c). This stripe of expression extends from the corticostriatal junction to approximately two-thirds of the length to the dorsal tip of the cortex, along a high ventral-low dorsal gradient. Interestingly, this approximates the distance cortical interneurons have migrated from the MGE at this age (Fig. 2a). In the ventral forebrain, $C d h 8$ is localized in the subventricular and ventricular ( $\mathrm{SVZ}$ and VZ) proliferative zones (PZ) of the ganglionic eminences (GE) (see arrowheads, Fig. 1b, c), suggesting that it may influence interneuron generation. In the medial and caudal sections, some weak staining in the mantles of the GEs can also be seen in agreement with previous work (Korematsu and Redies 1997a). Expression in the MGE interneuron progenitors was also confirmed by our recent RNA-sequencing data at E14.5 (unpublished data).

At E15.5, there is no longer any expression of $C d h 8$ in the PZ of the MGE (Fig. 1d-f). Instead, the expression is now found in the preoptic area (POA) and strongly in the striatum in rostral and medial sections, and in the globus pallidus (gp) caudally. In the cortex, $C d h 8$ is now more strongly expressed in the IZ, extending from the corticostriatal junction right around to the hippocampus throughout the entire rostro-caudal extent of the cortex (Fig. 1d-f). This, again, mirrors the distance that cortical interneurons have tangentially migrated in the IZ at this age (Fig. 2b).

By E18.5, $C d h 8$ expression in the cortex has split from one defined streak in the IZ into two, which approximately correspond to the SVZ and the lateral IZ/SP (Fig. 1g-i).
These are the two major interneuron migratory streams within the cortex before they move radially to populate the cortical plate (CP) (Faux et al. 2012). Thus, it appears that $C d h 8$ mRNA is expressed in the germinal zones where interneurons are generated in early development, but also along their major migratory routes into the cortex, suggesting that this cadherin may play a role in interneuron generation as well as migration.

To investigate expression of $C d h 8$ in interneurons themselves, we carried out fluorescent in situ hybridization in GAD67-GFP mice in which all interneurons express green fluorescent protein (Tamamaki et al. 2003). Our co-localization study at E13.5 shows that the expression of this cadherin closely follows the spatial distribution of cortical interneurons in the IZ stream (Fig. 2a). On closer examination, approximately $60 \%(58.28 \pm 3.6 \%)$ of cells in the IZ appear to express $C d h 8$ (arrows in Fig. 2e). In the ventral forebrain, we observe clear expression in the $\mathrm{PZ}$ and mantle of the MGE (white arrowheads in Fig. 2a), and colocalization with the endothelial cell marker IB4 (arrows in Fig. 2d). In the cortex at E15.5, Cdh8 is expressed strongly in the IZ cortical interneuron migratory stream (Fig. 2b), with approximately $50 \%(50 \pm 8.4 \%)$ of cells expressing $C d h 8$ mRNA (arrows in Fig. 2f). By E18.5, individual streams of interneurons are difficult to discern, though approximately $77.6 \pm 4.2 \%$ of GAD67-GFP ${ }^{+}$cells in the CP/SP appear to express Cdh8 mRNA (Fig. 2c, g-i).

The distribution of the $\mathrm{Cdh} 8$ protein mostly mirrors that of the mRNA throughout cortical development. This holds true particularly within the ventral forebrain, with strong expression seen in the MGE PZ at E13.5 (white arrowhead in Fig. 3a), and co-localization with several proliferation markers Ki67 and PH3 (Fig. 3g, h') and within the POA and striatum at E15.5 and E18.5 (Fig. 3b, c). However, it does differ in certain aspects, for example, whilst in situ hybridization at E13.5 and E15.5 shows expression in an area tightly restricted to the IZ stream, the antibody staining is much broader medio-laterally, perhaps along axonal projections within the cortex (Fig. 3e), and in some intermediate Tbr2 expressing progenitors (Fig. 3f). Approximately $70 \%(66.67 \pm 4.85 \%)$ of interneurons in the SVZ/IZ appear to express Cdh8 at E13.5 (white arrowheads in Fig. 3e), in a punctate manner, similar to cultured primary pyramidal neurons as previously reported (Friedman et al. 2015). The broader expression pattern of $\mathrm{Cdh} 8$ in the ventral forebrain appears to overlap with GAD67-GFP, at E15.5 and E18.5, suggesting that many migrating interneurons express this cadherin. Indeed, at E18.5, the majority of interneurons in the CP do appear to express Cdh8 $(77.78 \pm 9.2 \%)$ protein (white arrowheads in Fig. 3i, i"). 


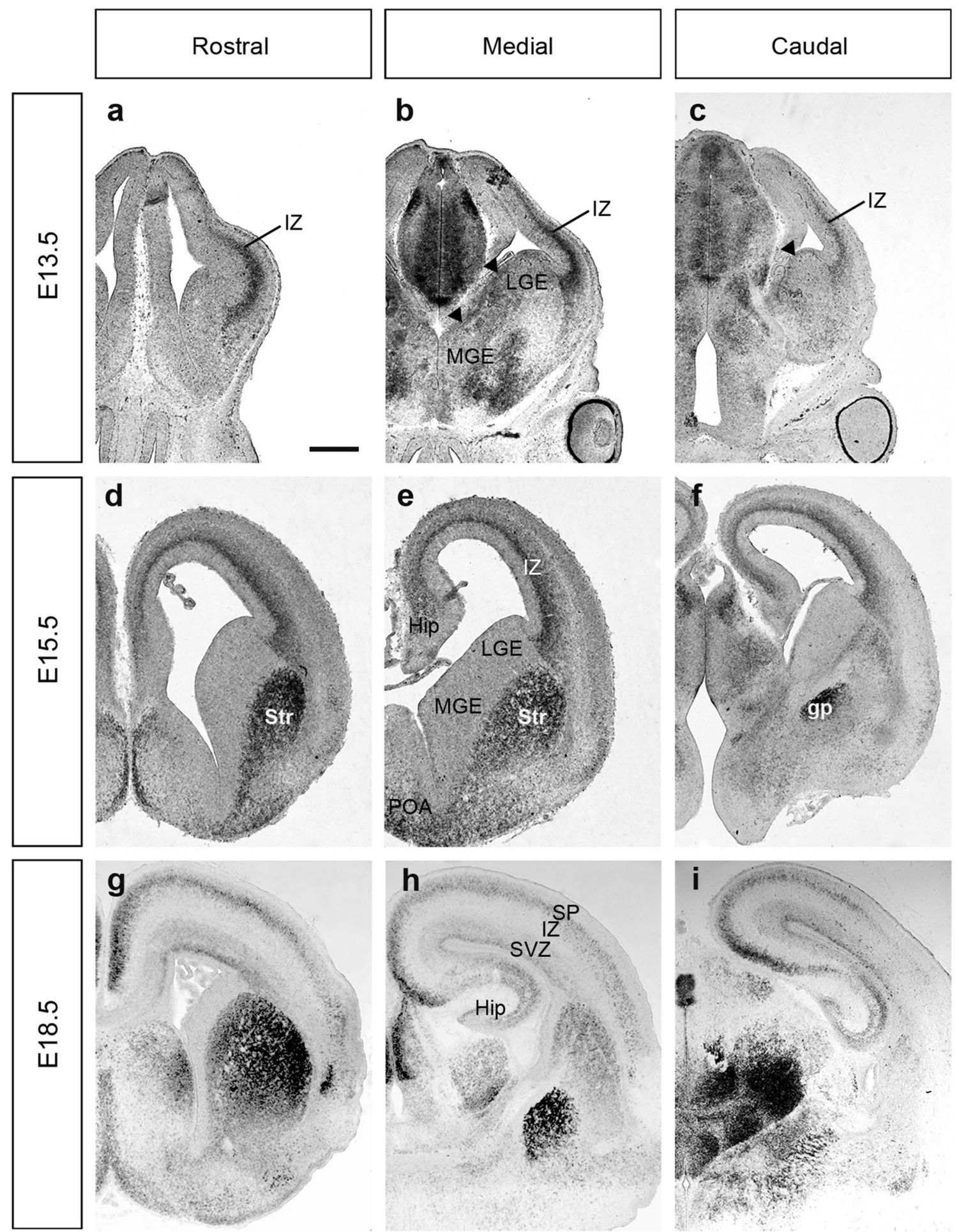

Fig. 1 In situ hybridization for $C d h 8$ mRNA expression in the developing forebrain. Coronal sections of the developing mouse forebrain at E13.5 (a-c), E15.5 (d-f) and E18.5 $(\mathbf{g}-\mathbf{i})$ showing the presence of $C d h 8$ mRNA at rostral (a, d, g), medial $(\mathbf{b}, \mathbf{e}, \mathbf{h})$ and caudal (c, f, i) levels. Arrowhead in b,c indicates expression in the proliferative zones. Scale bar in a: $500 \mu \mathrm{m}$ and is applicable to all sections. $G p$ globus pallidus, Hip hippocampus, $I Z$ intermediate zone, $L G E$ lateral ganglionic eminence, $M G E$ medial ganglionic eminence, $P O A$ preoptic area, $S P$ subplate, Str striatum, $S V Z$ subventricular zone 

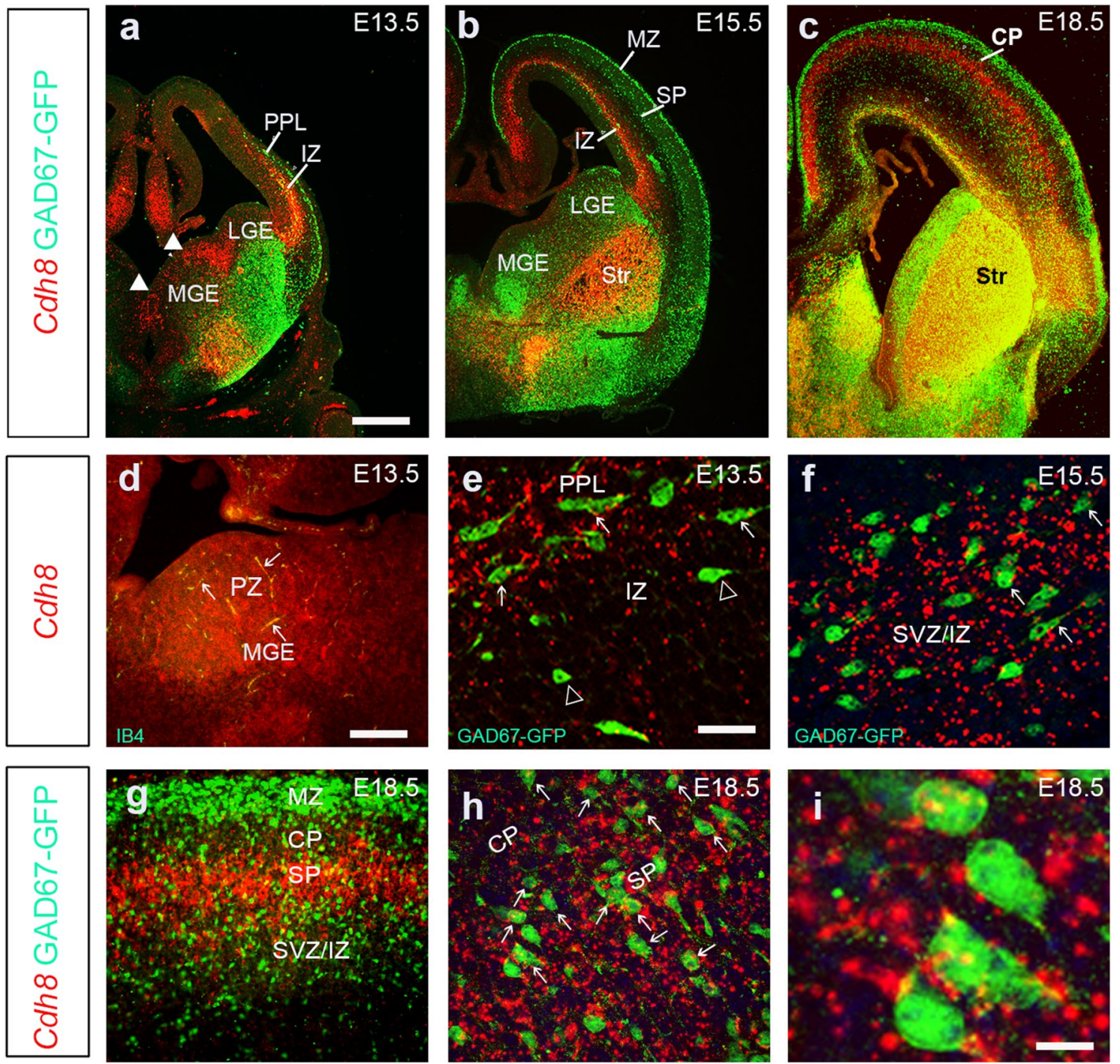

Fig. $2 \mathrm{Cdh} 8$ is expressed at the site of origin of interneurons and along their migratory routes. Fluorescent in situ hybridization for Cdh 8 mRNA on coronal sections from GAD67-GFP mouse forebrains at E13.5 (a, d, e), E15.5 (b, f) and E18.5 (c, g-i), showing Cdh8 expression (red) levels. Higher power images through cortex at E13.5 (e), E15.5 (f) and E18.5 (g-i); arrows indicate examples of interneurons that express $C d h 8$ mRNA and hollow-arrowheads $C d h 8$

\section{Altered interneuron number in the cortex of $\mathrm{Cdh}^{-/-}$ mice}

To determine if Cdh8 has an effect on cortical development, we first looked at the number and position of interneurons in the developing cortex of $C d h 8^{+/+}$and $C d h 8^{-/-}$mice, at late (E18.5) stage of development ( $n=3$ for each genotype), when we see the strongest expression of this gene in these cell types. Using in situ hybridization and immunochemistry for interneuron markers Lhx6 (Alifragis et al. 2004) and calbindin (CB) (Anderson et al. 1997), we assessed the number of interneurons within the developing cortex. We observed negative interneurons. E13.5 Expression of $C d h 8$ mRNA is observed in the proliferative zones (PZ), and to co-localize with the endothelial cell marker IB4 (d). Scale bar in a $500 \mu \mathrm{m}(\mathbf{a}-\mathbf{c})$; d is $200 \mu \mathrm{m}(\mathbf{d}, \mathbf{g})$; e is $100 \mu \mathrm{m}(\mathbf{e}-\mathbf{h})$, and $\mathbf{i}$ is $25 \mu \mathrm{m}$. $C P$ cortical plate, $I Z$ intermediate zone, $L G E$ lateral ganglionic eminence, $M G E$ medial ganglionic eminence, $M Z$ marginal zone, $P P L$ preplate layer, Str striatum, $S V Z$ subventricular zone

a significant increase in the total number of both $L h x 6^{+}$ $\left(C d h 8^{+/+} 235.84 \pm 6.23 ; C d h 8^{-/-} 261.5 \pm 4.89, p<0.0024\right)$ and $\mathrm{CB}^{+}\left(C d h 8^{+/+} 130.18 \pm 5.17 ; C d h 8^{-/-} 164.1 \pm 3.04\right.$, $p<0.0004$ ) and cells in the cortex at E18.5 (Fig. 4a-f). The distribution of Lhx6 cells within the different layers of the developing cortex was also altered, with a significant increase in cells in the $\mathrm{CP}\left(\mathrm{Cdh} 8^{+/+} 70.2 \pm 3.95\right.$; $C d h 8^{-/}-103.65 \pm 3.22, p<0.00005$ ) (Fig. 4c). We also observed changes in the distribution of $\mathrm{CB}^{+}$cells within cortical layers, with a significant increase in cells in the SVZ/IZ $\left(C d h 8^{+/+} 31.82 \pm 1.01 ; C d h 8^{-/-} 40.5 \pm 1.38\right.$, $p<0.009), \mathrm{CP}\left(C d h 8^{+/+} 39.27 \pm 1.71 ; C d h 8^{-/-} 52.7 \pm 1.27\right.$, 


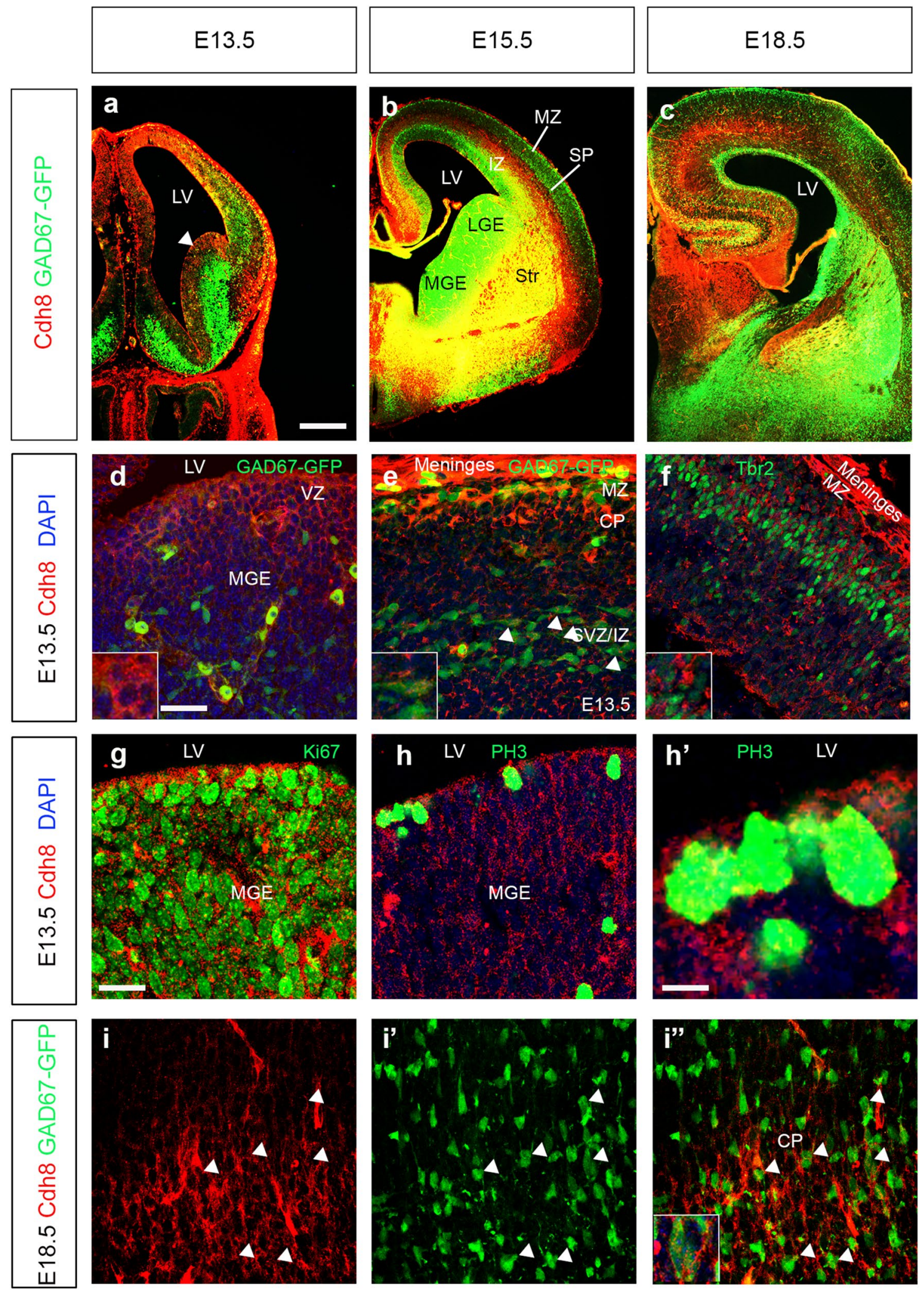

$p<0.0006)$ and marginal zone (MZ) $\left(C d h 8^{+/+} 24.36 \pm 0.86\right.$; $C d h 8^{-1-} 34.6 \pm 1.28, p<0.0006$ ) (Fig. 4f).
The increase in the number of $L h x \sigma^{+}$and $\mathrm{CB}^{+}$cells migrating into the neocortex of $C d h 8^{-/-}$mice could be due to an increase in proliferation or reduction in cell death. We 
4Fig. 3 Expression of Cdh8 protein in cortical interneurons. Coronal sections from GAD67-GFP mouse forebrains at E13.5 (a, d-h'), E15.5 (b) and E18.5 (c, i, i") were immunostained for Cdh8 protein (red). At E13.5, Cdh8 is strongly expressed in the ventral forebrain in the VZ of the MGE (d) and shows colocalization (yellow) with several proliferation markers $\mathrm{Ki} 67(\mathbf{g})$ and $\mathrm{PH} 3\left(\mathbf{h}, \mathbf{h}^{\prime}\right)$. In the cortex, Cdh8 co-localizes in GAD67 positive cells in the SVZ/IZ layer (e), and with some Tbr2 expressing intermediate progenitors (f). At E15.5 (b) and E18.5 (c) co-localization is observed in the basal telencephalon. At E18.5, the majority of interneurons in the CP (arrowheads in $\left.\mathbf{i}, \mathbf{i}^{\prime \prime}\right)$ express Cdh8 protein. Scale bar in $\mathbf{a}, 500 \mu \mathrm{m}(\mathbf{a}-\mathbf{c})$, $\mathbf{d}$ is $75 \mu \mathrm{m}$ $\left(\mathbf{d}-\mathbf{f}, \mathbf{i}, \mathbf{i}^{\prime \prime}\right), \mathrm{g}$ is $50 \mu \mathrm{m}(\mathbf{g}, \mathbf{h}), \mathbf{h}^{\prime}$ is $20 \mu \mathrm{m}$. $C P$ cortical plate, $I Z$ intermediate zone, $L G E$ lateral ganglionic eminence, $L V$ lateral ventricle, $M G E$ medial ganglionic eminence, $M Z$ marginal zone, $S P$ subplate, Str striatum, SVZIIZ subventricular/intermediate zone. VZ ventricular zone

suggest that the latter possibility is rather unlikely in view of the fact that, overall, little apoptosis is observed in the developing cortex, apart from the SVZ at birth and in the first two postnatal weeks (Thomaidou et al. 1997; Southwell et al. 2012). Increased proliferation is the most probable cause, as Cdh8 is expressed in the PZ of the GE at early stages of corticogenesis, suggesting it could regulate the proliferation of interneuron progenitors.

As we were unable to obtain additional knockout tissue for further experiments, we decided to apply the RNAi technique to investigate the role(s) of Cdh8 in corticogenesis. We designed four RNAi sequences (called S1-S4) that target four different regions within $C d h 8$ mRNA (Fig. 5a). To test the effectiveness of our siRNA constructs on Cdh8 expression, we transfected COS-7 cells with the over expressing, knockdown and mutated siRNA constructs (at a ratio of 1:3). $48 \mathrm{~h}$ after transfection, we assessed the level of Cdh8 mRNA and protein in these cells. We observed a significant reduction in both Cdh8 mRNA and protein with knockdown constructs S1-S3, but not S4 or with mutated S1 sequence (S1m), which can serve as control for the siRNA transfections (Fig. 5b). These constructs were used in further in vitro experiments to assess the role of Cdh8 in proliferation and apoptosis.

\section{Loss of Cdh8 function increases proliferation in neuronal cultures}

To examine the effects of over expressing or silencing Cdh8 on cell migration, proliferation and apoptosis, Cdh8GFP cDNA or control (pCDNA3.1-GFP), and S1 siRNA (GFP) or mutated Sl siRNA (GFP) (S1m) were introduced into E14 rat (equivalent to mouse E12.5) MGE-dissociated neural progenitors in order to examine proliferation or into E17 (equivalent to mouse E15.5) MGE cultures to assess for migration and apoptosis. After 2 days in vitro (2DIV), cells were stained for Nestin (neuronal progenitor marker) and PH3 (proliferation marker) to look at proliferation, or
CB (interneuron) and CC3 (apoptotic) markers to identify apoptotic interneurons. Over-expressing (pCDNA3.1 $18.01 \pm 7.43 \%, \mathrm{Cdh} 819.64 \pm 7.07 \%, p<0.2$ ) or knocking down $(\mathrm{S} 1 \mathrm{~m} 23.15 \pm 7.5 \%, \mathrm{~S} 136.21 \pm 5.21 \%, p<0.165) \mathrm{Cdh} 8$ expression did not have a significant effect on the level of apoptosis in our cultures (Fig. 5d). However, altering Cdh8 levels had a significant effect on proliferation. Over expressing Cdh8 resulted in decreased (pCDNA3.1 73.98 $\pm 4.24 \%$, Cdh8 $53.3 \pm 4.12 \%, p=0.0004)$, whilst knockdown led to increased proliferation $(\mathrm{S} 1 \mathrm{~m} 70.64 \pm 2.25 \%, \mathrm{~S} 1$ $78.23 \pm 2.8 \%, p=0.006)$ of the transfected progenitors in the dissociated cultures (Fig. 5e). To assess migration we used a chemomigration assay. In these experiments we found alteration of Cdh8 levels in MGE interneurons had no affect on their migratory potential (Fig. 5c) These findings are in agreement with our knockout mouse studies, where we observe increased number of interneurons in the cortex, most probably due to increased proliferation and generation of more interneurons.

Next, we wanted to determine whether the observed increase in proliferation was specific to cortical interneurons or whether it applied to other migrating neuronal cell types. In previous studies, we have used the immortalized gonadotropin-releasing hormone secreting $(\mathrm{GnRH})$ neurons (GN11 cells) to look at the effects of factors on migration (Hernandez-Miranda et al. 2011) and on proliferation/ apoptosis (Cariboni et al. 2011), as they share a common repertoire of genes with cortical interneurons and exhibit a similar migratory behavior. We found that these cells, such as interneurons, expressed Cdh8 mRNA as established by reverse transcription-PCR (Fig. 6a) and protein by immunohistochemistry (Fig. 6b).

In terms of proliferation we observed a small, but significant decrease in the number of $\mathrm{PH}^{+}$cells following over-expression of Cdh8 (pCDNA3.1 70.57 $\pm 5.44 \%, \mathrm{Cdh} 8$ $57.8 \pm 5.99 \%, p=0.007$ ) in GN11 cells (Fig. 6c). Interestingly, Cdh8 knockdown resulted in increased proliferation (S1m 52.14 $\pm 8.85 \%, \mathrm{~S} 174.59 \pm 5.98 \%, p=0.0004)$ of the transfected cells in the GN11 cultures, which is in agreement with our observations in MGE neuronal progenitors. The effect of altering Cdh8 levels on GN11 cell proliferation appears stronger than on interneuron progenitors; possibly due to the homogeneity of the GN11 population (all cells express Cdh8). In our hypoxic cultures, apoptosis was reduced when Cdh8 was over-expressed (CC3: pCDNA3.1 $70.78 \pm 1.68 \%, \mathrm{Cdh} 853.15 \pm 3.35 \%, p=0.0001)$, but not when it was knocked down (S1m 70.22 $\pm 3.28 \%, \mathrm{~S} 1$ $68.76 \pm 5.32 \%, p=0.89$, Fig. $6 d)$.

A previous study demonstrated that over-expression of two dominant negative constructs of NCAD and CAD11 slowed down the migration of lateral reticular nucleus and external cuneate nucleus (LRN/ECN) neurons, while overexpression of these cadherins had no effect (Taniguchi 

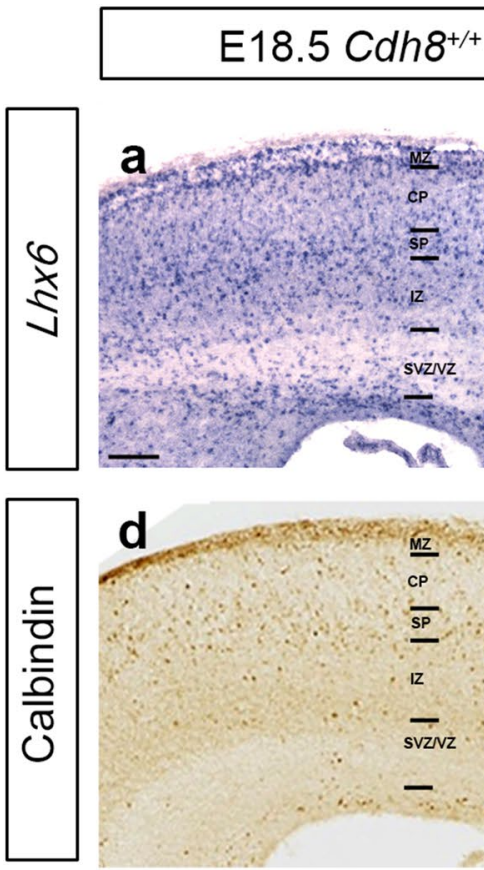
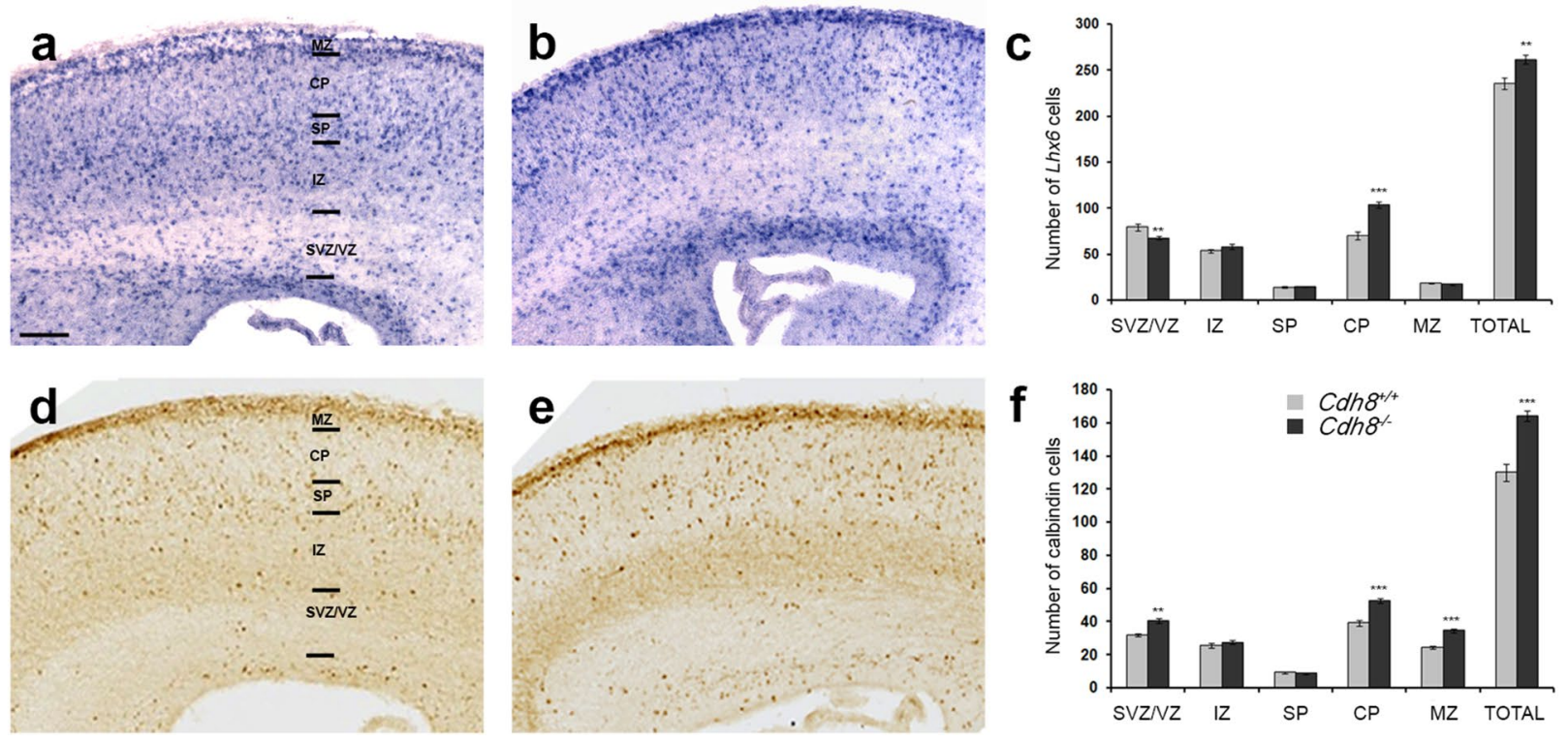

Fig. 4 Increased number of interneurons in the cortex of $C d h 8^{-/-}$ mice. Images of in situ hybridization for $\operatorname{Lh} x 6(\mathbf{a}, \mathbf{b})$ and immunohistochemistry for calbindin (d, e) in coronal brain sections from $C d h 8^{+/+}(\mathbf{a}, \mathbf{d})$ and $C d h 8^{-/-}(\mathbf{b}, \mathbf{e})$ mice at E18.5. c, f Quantification of Lhx6 (c) and calbindin (f) positive cells in the cortex show an

et al. 2006). Here, we wanted to see if altering Cdh8 levels affected GN11 cell migration using a chemomigration assay. We found that altering Cdh8 expression in these cells had no effect on their migratory ability (pCDNA3.1 $43.45 \pm 6.97 \%$, $\mathrm{Cdh} 845.83 \pm 6.7 \%, p=0.808 ; \mathrm{S} 1 \mathrm{~m} 45.04 \pm 7.85 \%, \mathrm{~S} 1$ $52.38 \pm 9.88 \%, p=0.57$ ) (Fig. 6e), supporting the idea that Cadh8 is not involved in neuronal migration, which is in agreement with our interneuron migration data (Fig. 5c). Taken together, our data suggest that altering Cdh8 levels significantly affects their proliferative potential.

To confirm these results, we used an alternative approach that does not rely on the transfection efficiency of the dissociated progenitors, but in the functional blocking of Cdh8 through the application of Cdh8-Fc protein. Interneuron progenitors dissociated from mouse E12.5 GEs were treated with $1 \mu \mathrm{g} / \mathrm{ml} \mathrm{Cdh} 8-\mathrm{Fc}$ or IgG (control) for two DIV and BrdU was added to the media $2 \mathrm{~h}$ before fixation. Counts of cells stained for BrdU or the general proliferation marker Ki67 showed increased proliferation in Cadh8-Fc treated cultures when compared to control treatments (Ki67: Cdh8-Fc 36.45 $\pm 1.42 \%$, IgG $22.3 \pm 1.6 \%, p=0.0001$, BrdU: Cdh8-Fc $20.1 \pm 1.2 \%$, $\operatorname{IgG} 16.2 \pm 0.9 \%, p=0.02, n=3$ ) (Fig. 7a-c). These results were further corroborated by qPCR with RNA extracted from $\mathrm{Cdh} 8-\mathrm{Fc}$ treated cultures versus IgG controls. Genes increased number at E18.5 when compared to $C d h 8^{+/+}$controls. Scale bars in $\mathbf{a}$ is $200 \mu \mathrm{m}(* * p<0.001, * * * p<0.0001)$. Error bars indicate SEM. $C P$ cortical plate, $I Z$ intermediate zone, $M Z$ marginal zone, $S V Z / V Z$ subventricular zone/ventricular zone

involved in proliferation, cell cycle progression and pluripotency showed an increase in their expression (Ki67 twofold, Sox 2 threefold, CyclinD1 fivefold, Fig. 7d); Gad1 also showed a sevenfold increase in expression, suggesting an increase in the number of interneurons in these cultures (Fig. 7d). Cell cycle kinetics analysis showed that the cycle length was not affected in the Cdh8-Fc treated cells (when compared to controls), but fewer cells exited the cycle in the Cdh8-Fc treated cultures (Cdh8-Fc 6.1\%, IgG 11.5\%). Finally, to further verify the effect of Cdh8 on the proliferation of interneurons, we treated E13.5 mouse cortical slices with Cdh8-Fc or IgG for $24 \mathrm{~h}$ and counted the number of proliferating cells in the VZ and SVZ in both conditions. We found that Cdh8-Fc treated slices had increased numbers of $\mathrm{Ki}^{+} 7^{+}$cells in the $\mathrm{VZ}$ and $\mathrm{SVZ}$ of the MGE (Ki67, VZ: Cdh8-Fc 51.6 \pm 3.8, IgG 34.2 $\pm 4.2, p=0.02$, SVZ: Cdh8-Fc 50.1 $\pm 6.1, \operatorname{IgG} 29.3 \pm 5.2, p=0.0012)$ and more $\mathrm{PH}^{+}{ }^{+}$cells in the SVZ $\left(\mathrm{PH}^{+}:\right.$Cdh $8-\mathrm{Fc} 18.33 \pm 1.8$, IgG $10.8 \pm 1.99, p=0.01$ ) (Fig. $7 \mathrm{e}-\mathrm{g}$ ).

Taken together, our data suggest that Cdh8 does not play a significant role in migration or apoptosis of interneurons within the developing cortex or in vitro, but altering Cdh8 levels significantly affects the proliferative potential of these cells. 
a
s1 GCTGGCACAATCTTTCAAA
S2 GCACTATTCGAAATCA
S3 GCAGATGATGGGAAGATAA
S4 GCGCATCCGAATATGAGGCAT
S1m GCTGGCAGTATCTATCAAA

b

cos-7 cells

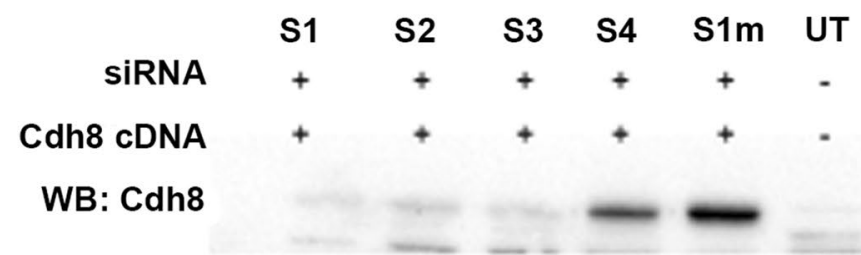

WB: Gapdh
C

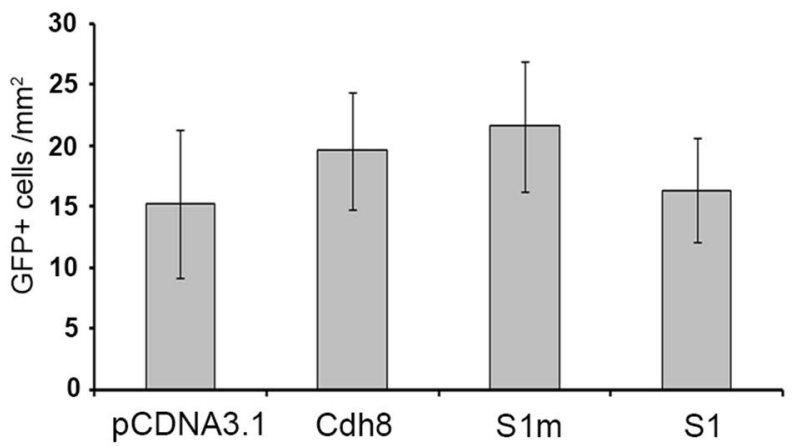

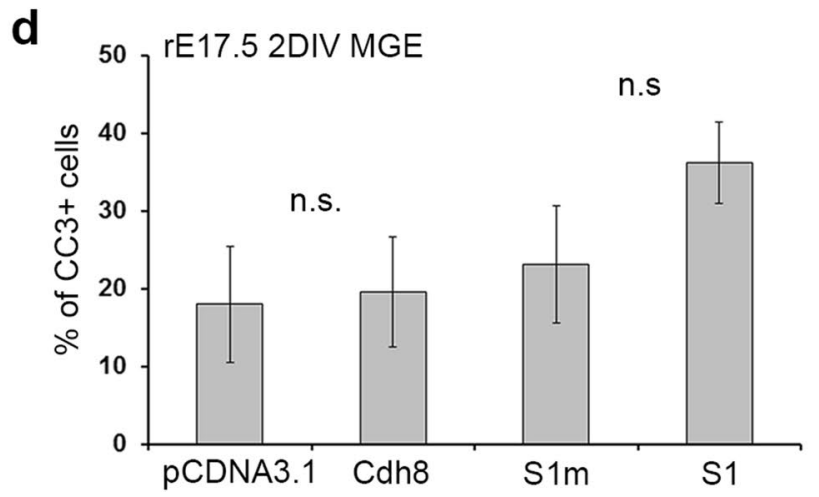

Fig. 5 Suppression of Cdh8 protein expression by siRNAs affects the proliferation of interneuron progenitors. a Sequences of specific and triple-point-mutated siRNAs targeting mouse Cdh8 mRNA. b Western blot shows the effectiveness of S1, S2 and S3, but not S4 or S1-mutated (S1m) sequence at knocking down Cdh8 mRNA expression in COS-7 cells. c Quantification of rE17.5 MGE interneuron cell migration in a Boyden's chamber following transfection with

\section{Discussion}

Corticogenesis involves the production, maintenance and arrangements of pyramidal neurons and interneurons into precise cortical circuits. Disruption to this delicate balance may result in wide-ranging neurological and cognitive defects. Thus, there has been considerable interest over the years on the molecular mechanisms that underlie their tangential and radial migration, and an ever-increasing list of molecules that play important roles in their generation, differentiation and migration (Faux et al. 2012; Marin 2013; Guo and Anton 2014). However, little is known about the molecules involved in interneuron migratory stream specification. In an attempt to address this point, we previously

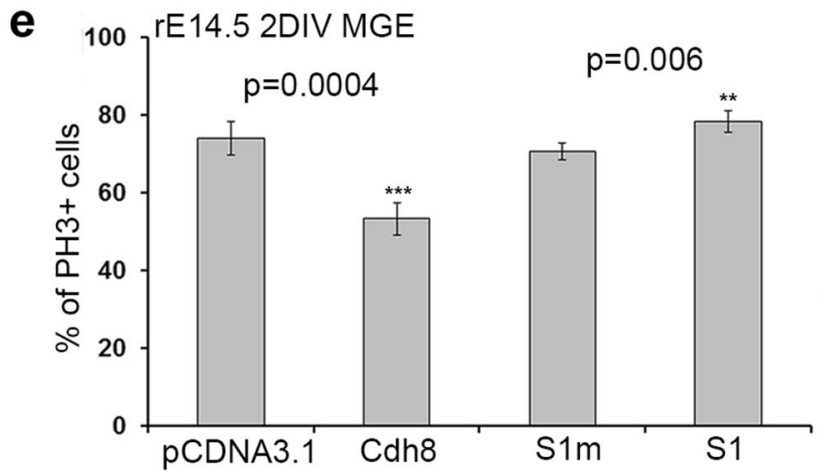

either Cdh8 over expressing, knockdown or control constructs. d, e Histogram shows the percentage of rE17.5 MGE interneuron cultures $\left(\mathrm{CB}^{+} / \mathrm{GFP}^{+}\right)$that are apoptotic $\left(\mathrm{CC}^{+}\right)(\mathbf{d})$, and rE14.5 MGE neuronal progenitors $\left(\mathrm{Nestin}^{+} / \mathrm{GFP}^{+}\right)$that are proliferating $\left(\mathrm{PH}^{+}\right)$ (e), following 2 days in vitro (2DIV) after transfection with either over-expressing, knockdown or control constructs $(* * p<0.001$, $* * * p<0.0001)$. Error bars indicate SEM

carried out a microarray study and identified several members of the cadherin family which were differentially expressed, including Cdh8.

Cadherins are a superfamily of more than 100 transmembrane glycoproteins originally identified as cell adhesion molecules (Takeichi 2007; Hirano and Takeichi 2012). Functional studies have revealed that they are involved in neural patterning, cell migration, axon guidance, and synapse formation and function (Nakagawa and Takeichi 1998; Manabe et al. 2000; Inoue et al. 2001; Treubert-Zimmermann et al. 2002; Suzuki et al. 2007; Barnes et al. 2010; Osterhout et al. 2011; Williams et al. 2011; Kuwako et al. 2014). With the exception of a few cadherins, such as N-cadherin (Luccardini et al. 2013) and Celsr3 (Ying et al. 2009), which have 
a

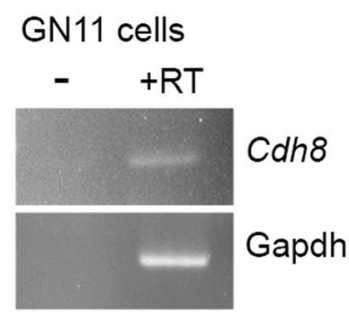

b

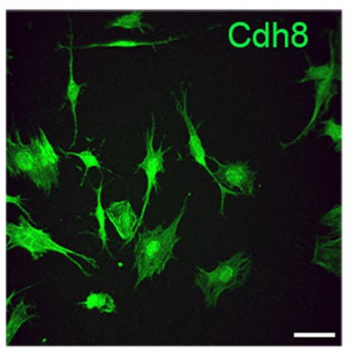

C

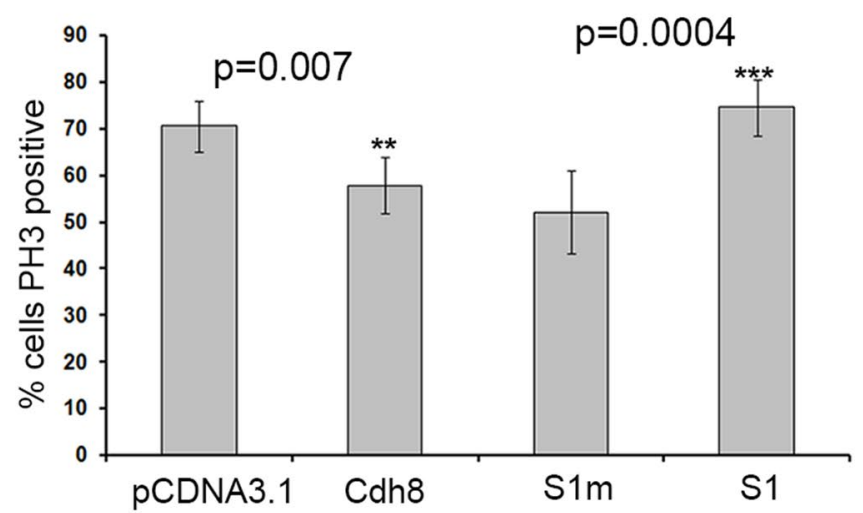

e

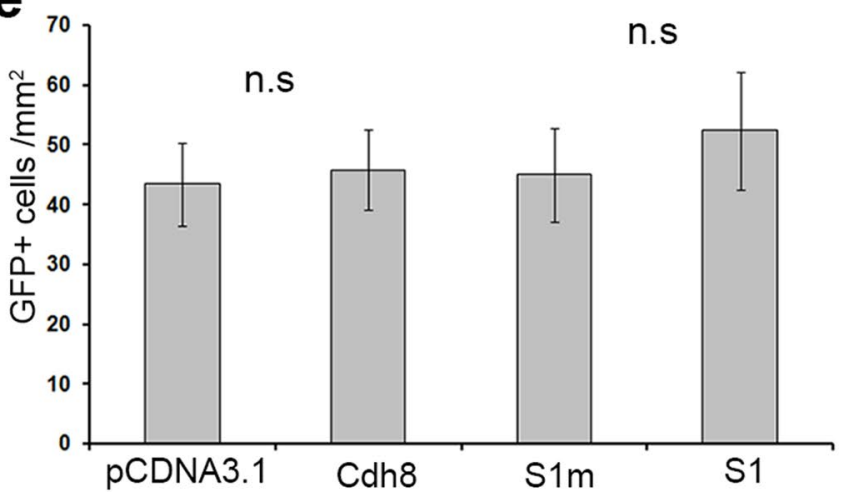

Fig. 6 Cdh8 is expressed by GN11 cells and affects their proliferation. a Reverse transcription-PCR analysis showed expression of $C d h 8$ in GN11 cells. b Immunohistochemistry confirmed the expression of Cdh8 in GN11 cells. c, d Histograms show percentage of proliferating $\left(\mathrm{GFP}^{+} / \mathrm{PH}^{+}\right)(\mathbf{c})$, and apoptotic $\left(\mathrm{GFP}^{+} / \mathrm{CC}^{+}\right)$ (d) cells following transfection with either over expressing, knockdown or control constructs. e Quantification of GN11 cell migration in a Boyden's chamber following transfection with either Cdh8 over expressing, knockdown or control constructs. Scale bar in $b$ is $100 \mu \mathrm{m}$. $(* * p<0.001, * * * p<0.0001)$. Error bars indicate SEM

in corticogenesis and in the development of the disorder. However, the role of Cdh8 in interneuron development and potential contribution to autism has not been assessed.

To address this, we first used in situ hybridization and immunohistochemistry to expand on previous studies (Korematsu and Redies 1997a, b; Korematsu et al. 1998a, b; Medina et al. 2004; Lefkovics et al. 2012) and examined the expression of $\mathrm{Cdh} 8$ during cortical development. These experiments revealed the presence of $\mathrm{Cdh} 8$ in progenitor cells lining the ventricular surface of the GEs as early as E13.5, as well in the majority of migrating interneurons, suggesting it may play a role in their generation and/or migration.

To assess whether Cdh8 affect interneuron development, we analyzed mice depleted of this cadherin. This analysis of $C d h 8^{-l-}$ mice revealed an increased number of interneurons in the cortex at the end of corticogenesis, a defect that could be due to a number of factors including altered migration, reduced apoptosis and/or increased proliferation. Cdh 8 has been shown to play a role in the migration 
Fig. 7 Proliferation of cortical interneuron progenitors is increased after treatment with Cdh8-Fc. a, b E12.5 mouse GEderived dissociated interneuron progenitor cultures treated with IgG (control) or Cdh8-Fc were labelled for BrdU and Ki67. c Graph shows increased numbers of $\mathrm{BrdU}^{+}$and $\mathrm{Ki}^{+} 7^{+}$proliferating cells following Cdh8-Fc treatment. d Quantitative-PCR shows increased levels of expression for proliferation, cell cycle, stem cell and interneuron genes, in cells treated with Cdh8-Fc for 2DIV when compared to treatment with IgG (control). e, f E13.5 mouse cortical slices were treated for $24 \mathrm{~h}$ with $\operatorname{IgG}(\mathbf{e})$ or $\mathrm{Cdh} 8-\mathrm{Fc}$ (f) were labelled with anti-PH3 or Ki67 antibody, photographed at the level of MGE. g Quantification of $\mathrm{Ki}^{+} 7^{+}$and $\mathrm{PH}^{+}$cells in the VZ and $\mathrm{SVZ}$ of MGE revealed a significant increase in the proliferation of MGE cells after Cdh8-Fc treatment. Scale bar in a, $50 \mu \mathrm{m}(\mathbf{a}$, b, e, f) $\left({ }^{*} p<0.01,{ }^{* *} p<0.001\right.$, $* * * p<0.0001)$. Error bars indicate SEM. SVZ subventricular zone, $V Z$ ventricular zone
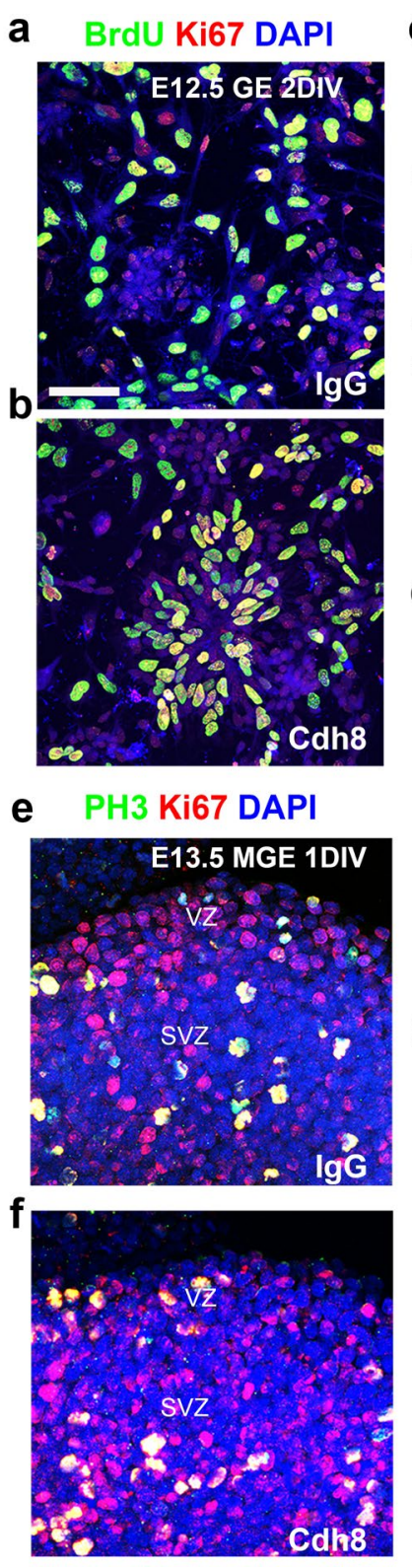

C
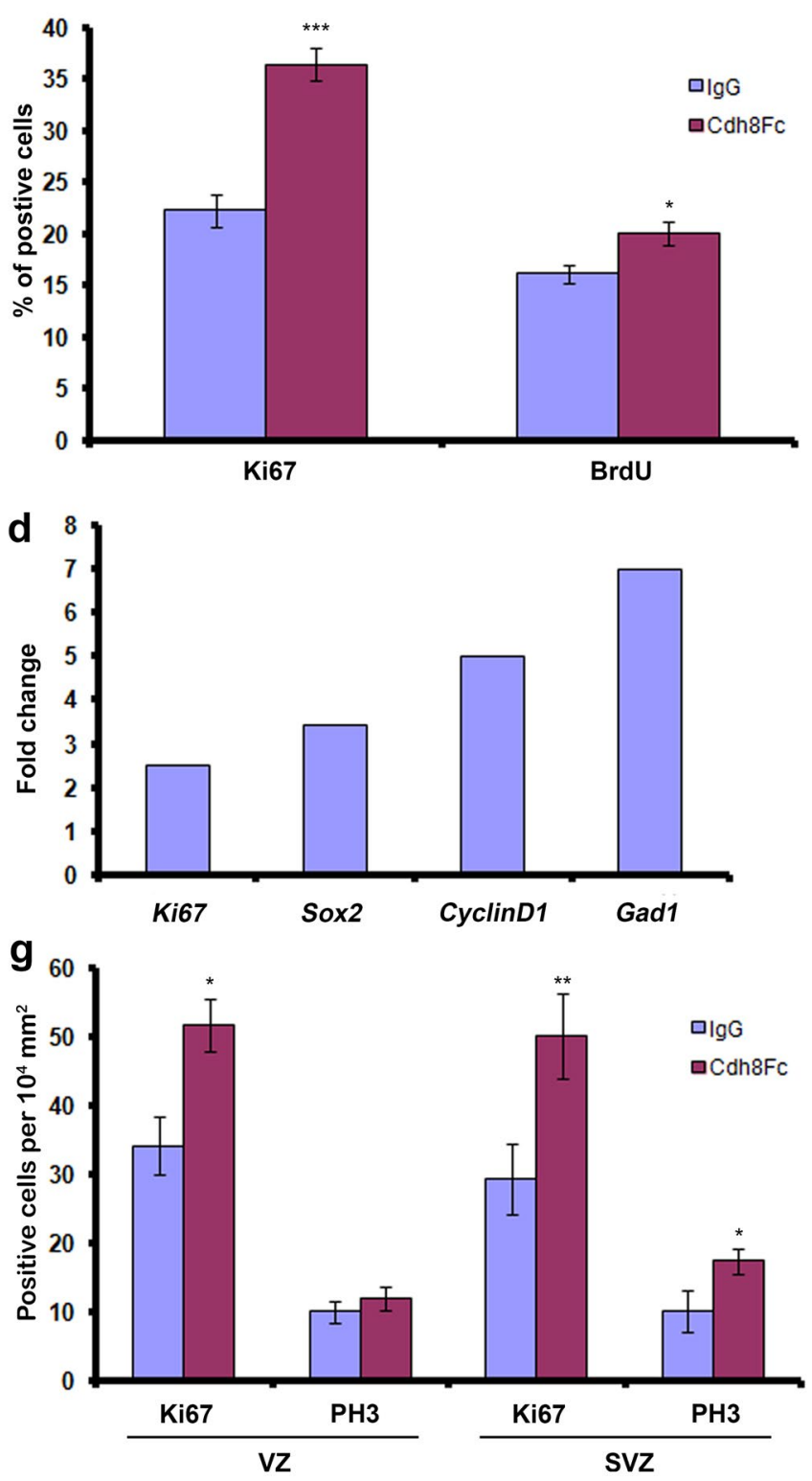

of facial branchiomotor neurons in the mouse hindbrain (Garel et al. 2000) and, more recently, has been implicated in the migration of facial neurons, as volproic acid treatment hindered their migration, which coincided with decreased Cdh8 mRNA levels (Oyabu et al. 2013). Cdh8 has also been implicated in metastasis in non-small cell lung cancer $(\mathrm{Lu}$ et al. 2006). Whilst these studies have suggested a role for Cdh8 in cell migration, our in vitro experiments did not support such a role in cortical interneurons or GN11 cells, indicating either altered apoptosis or proliferation are most likely responsible for the increased number of interneurons observed in the cortex of $C d h 8^{-/-}$mice. Since apoptosis in developing cortical interneurons occurs mainly in the first postnatal days and is intrinsically regulated (Southwell et al. 2012; Thomaidou et al. 1997), we reasoned that the increased number of interneurons in the E18.5 $\mathrm{Cdh8^{-/- }}$ mice is not due to reduced apoptosis. Indeed, reduction of $\mathrm{Cdh} 8$ levels in our vitro experiments did not affect interneuron apoptosis.

The expression of Cdh8 in the proliferative zones of the MGE points to a role in proliferation. Indeed, we observed in our in vitro experiments that over the expression of Cdh8 levels decreased proliferation and knockdown had the opposite effect. This latter finding is in accordance with recent studies which demonstrated that knocking down CDH8 expression in gastric cancer cell lines, MKN45 and NUGC4, promoted proliferation (Sawada et al. 2013). Similarly, expression of a dominant negative form of Ncad in chicken spinal cord caused loss of cadherin-based adhesions in the apical end-feet of neuron progenitors, which resulted 
in increased proliferation and neuron numbers (Hatakeyama et al. 2014). Furthermore, removal of Cdh2 leads to dramatic increase in proliferation of cortical neurons, leading to the formation of a double-cortex (Gil-Sanz et al. 2014), highlighting the importance of maintenance of adherens junctions for the control of cell proliferation in the developing brain. On the other hand, Cadh 13 was implicated in the regulation of programmed cell death and survival in the developing forebrain (Killen et al. 2017), pointing to the many different or even opposite functions of Cadherins during brain development. In summary, we report here that Cdh8 deficient mice have increased numbers of interneurons in their cortex due to increased proliferation of their progenitors. Our findings support a novel role for Cdh8 in neurogenesis in the ventral telencephalon during development.

Acknowledgements We would like to thank the following for supplying transgenic mouse lines: Yuchio Yanagawa and Kunihiko Obata (GAD67-GFP), and Sachihiro C. Suzuki (Cdh8). Funding for the research was provided by a Grant from the Biotechnology and Biological Sciences Research Council (BBSRC; BB/M009424/1 to J.G.P. and W.D.A.)

Author contributions FM, ACK, and WDA designed the experiments. FM, ACK, MB and WDA performed and analyzed the experiments. FM, JGP and WDA wrote the manuscript with input from the co-authors.

\section{Compliance with ethical standards}

Ethical standards All experimental procedures were performed in accordance with the UK Animals (Scientific Procedures) Act 1986 and institutional ethical guidelines.

Conflict of interest The authors declare that they have no conflict of interest.

Open Access This article is distributed under the terms of the Creative Commons Attribution 4.0 International License (http://creativeco mmons.org/licenses/by/4.0/), which permits unrestricted use, distribution, and reproduction in any medium, provided you give appropriate credit to the original author(s) and the source, provide a link to the Creative Commons license, and indicate if changes were made.

\section{References}

Alifragis P, Liapi A, Parnavelas JG (2004) Lhx6 regulates the migration of cortical interneurons from the ventral telencephalon but does not specify their GABA phenotype. J Neurosci 24:5643-5648

Anderson SA, Eisenstat DD, Shi L, Rubenstein JL (1997) Interneuron migration from basal forebrain to neocortex: dependence on Dlx genes. Science 278:474-476

Andrews WD, Zito A, Memi F, Jones G, Tamamaki N, Parnavelas JG (2013) Limk2 mediates semaphorin signalling in cortical interneurons migrating through the subpallium. Biol Open 2:277282. https://doi.org/10.1242/bio.20133202
Antypa M, Faux C, Eichele G, Parnavelas JG, Andrews WD (2011) Differential gene expression in migratory streams of cortical interneurons. Euro J Neurosci 34:1584-1594. https://doi.org/10. 1111/j.1460-9568.2011.07896.x

Barnes SH, Price SR, Wentzel C, Guthrie SC (2010) Cadherin-7 and cadherin-6B differentially regulate the growth, branching and guidance of cranial motor axons. Development 137:805-814. https ://doi.org/10.1242/dev.042457

Bekirov IH, Nagy V, Svoronos A, Huntley GW, Benson DL (2008) Cadherin- 8 and $\mathrm{N}$-cadherin differentially regulate pre- and postsynaptic development of the hippocampal mossy fiber pathway. Hippocampus 18:349-363. https://doi.org/10.1002/hipo.20395

Benes FM, Berretta S (2001) GABAergic interneurons: implications for understanding schizophrenia and bipolar disorder. Neuropsychopharmacology 25:1-27

Cariboni A, Davidson K, Dozio E, Memi F, Schwarz Q, Stossi F, Parnavelas JG, Ruhrberg C (2011) VEGF signalling controls GnRH neuron survival via NRP1 independently of KDR and blood vessels. Development 138:3723-3733. https://doi.org/10.1242/ dev.063362

Cavanagh JF, Mione MC, Pappas IS, Parnavelas JG (1997) Basic fibroblast growth factor prolongs the proliferation of rat cortical progenitor cells in vitro without altering their cell cycle parameters. Cereb Cortex 7:293-302

Chuang HC, Huang TN, Hsueh YP (2015) T-brain-1-a potential master regulator in autism spectrum disorders. Autism Res 8:412-426. https://doi.org/10.1002/aur.1456

Cossart R, Bernard C, Ben-Ari Y (2005) Multiple facets of GABAergic neurons and synapses: multiple fates of GABA signalling in epilepsies. Trends Neurosci 28:108-115. https://doi. org/10.1016/j.tins.2004.11.011

Faux C, Rakic S, Andrews W, Yanagawa Y, Obata K, Parnavelas JG (2010) Differential gene expression in migrating cortical interneurons during mouse forebrain development. J Comp Neurol 518:1232-1248. https://doi.org/10.1002/cne.22271

Faux C, Rakic S, Andrews W, Britto JM (2012) Neurons on the move: migration and lamination of cortical interneurons. Neurosignals 20:168-189. https://doi.org/10.1159/000334489

Friedman LG, Riemslagh FW, Sullivan JM, Mesias R, Williams FM, Huntley GW, Benson DL (2015) Cadherin-8 expression, synaptic localization, and molecular control of neuronal form in prefrontal corticostriatal circuits. J Comp Neurol 523:75-92. https://doi.org/10.1002/cne.23666

Gant JC, Thibault O, Blalock EM, Yang J, Bachstetter A, Kotick J, Schauwecker PE, Hauser KF, Smith GM, Mervis R, Li Y, Barnes GN (2009) Decreased number of interneurons and increased seizures in neuropilin 2 deficient mice: implications for autism and epilepsy. Epilepsia 50:629-645. https://doi.org/ 10.1111/j.1528-1167.2008.01725.x

Garel S, Garcia-Dominguez M, Charnay P (2000) Control of the migratory pathway of facial branchiomotor neurones. Development 127:5297-5307

Gil-Sanz C, Landeira B, Ramos C, Costa MR, Muller U (2014) Proliferative defects and formation of a double cortex in mice lacking Mltt4 and Cdh2 in the dorsal telencephalon. J Neurosci 34:10475-10487. https://doi.org/10.1523/jneur osci.1793-14.2014

Guo J, Anton ES (2014) Decision making during interneuron migration in the developing cerebral cortex. Trends Cell Biol 24:342-351. https://doi.org/10.1016/j.tcb.2013.12.001

Hatakeyama J, Wakamatsu Y, Nagafuchi A, Kageyama R, Shigemoto R, Shimamura K (2014) Cadherin-based adhesions in the apical endfoot are required for active Notch signaling to control neurogenesis in vertebrates. Development 141:1671-1682. https://doi. org/10.1242/dev. 102988 
Hernandez-Miranda LR, Cariboni A, Faux C, Ruhrberg C, Cho JH, Cloutier JF, Eickholt BJ, Parnavelas JG, Andrews WD (2011) Robo1 regulates semaphorin signaling to guide the migration of cortical interneurons through the ventral forebrain. J Neurosci 31:6174-6187. https://doi.org/10.1523/JNEUR OSCI.5464-10.2011

Hirano S, Takeichi M (2012) Cadherins in brain morphogenesis and wiring. Physiol Rev 92:597-634. https://doi.org/10.1152/physr ev.00014.2011

Huang TN, Chuang HC, Chou WH, Chen CY, Wang HF, Chou SJ, Hsueh YP (2014) Tbr1 haploinsufficiency impairs amygdalar axonal projections and results in cognitive abnormality. Nat Neurosci 17:240-247. https://doi.org/10.1038/nn.3626

Huntley GW, Elste AM, Patil SB, Bozdagi O, Benson DL, Steward O (2012) Synaptic loss and retention of different classic cadherins with LTP-associated synaptic structural remodeling in vivo. Hippocampus 22:17-28. https://doi.org/10.1002/hipo.20859

Inoue T, Tanaka T, Takeichi M, Chisaka O, Nakamura S, Osumi N (2001) Role of cadherins in maintaining the compartment boundary between the cortex and striatum during development. Development 128:561-569

Kido M, Obata S, Tanihara H, Rochelle JM, Seldin MF, Taketani S, Suzuki ST (1998) Molecular properties and chromosomal location of cadherin-8. Genomics 48:186-194

Killen AC, Barber M, Paulin JJW, Ranscht B, Parnavelas JG, Andrews WD (2017) Protective role of Cadherin 13 in interneuron development. Brain Struct Funct 222:3567-3585. https://doi.org/10.1007/ s00429-017-1418-y

Korematsu K, Redies C (1997a) Expression of cadherin-8 mRNA in the developing mouse central nervous system. J Comp Neurol 387:291-306

Korematsu K, Redies C (1997b) Restricted expression of cadherin-8 in segmental and functional subdivisions of the embryonic mouse brain. Dev Dyn 208:178-189

Korematsu K, Goto S, Okamura A, Ushio Y (1998a) Heterogeneity of cadherin-8 expression in the neonatal rat striatum: comparison with striatal compartments. Exp Neurol 154:531-536

Korematsu K, Nishi T, Okamura A, Goto S, Morioka M, Hamada J, Ushio Y (1998b) Cadherin-8 protein expression in gray matter structures and nerve fibers of the neonatal and adult mouse brain. Neuroscience 87:303-315

Kuwako K, Nishimoto Y, Kawase S, Okano HJ, Okano H (2014) Cadherin-7 regulates mossy fiber connectivity in the cerebellum. Cell Rep 9:311-323

Lefkovics K, Mayer M, Bercsenyi K, Szabo G, Lele Z (2012) Comparative analysis of type II classic cadherin mRNA distribution patterns in the developing and adult mouse somatosensory cortex and hippocampus suggests significant functional redundancy. J Comp Neurol 520:1387-1405. https://doi.org/10.1002/cne.22801

Livak KJ, Schmittgen TD (2001) Analysis of relative gene expression data using real-time quantitative PCR and the 2(-Delta Delta C(T)) Method. Methods 25:402-408

Lu Y, Lemon W, Liu PY, Yi YJ, Morrison C, Yang P, Sun ZF, Szoke J, Gerald WL, Watson M, Govindan R, You M (2006) A gene expression signature predicts survival of patients with stage I non-small cell lung cancer. PLoS Med 3:2229-2243

Luccardini C, Hennekinne L, Viou L, Yanagida M, Murakami F, Kessaris N, Ma X, Adelstein RS, Mege RM, Metin C (2013) N-cadherin sustains motility and polarity of future cortical interneurons during tangential migration. J Neurosci 33:18149-18160. https://doi. org/10.1523/jneurosci.0593-13.2013

Manabe T, Togashi H, Uchida N, Suzuki SC, Hayakawa Y, Yamamoto M, Yoda H, Miyakawa T, Takeichi M, Chisaka O (2000) Loss of cadherin-11 adhesion receptor enhances plastic changes in hippocampal synapses and modifies behavioral responses. Mol Cel Neurosci 15:534-546. https://doi.org/10.1006/mcne.2000.0849
Marin O (2013) Cellular and molecular mechanisms controlling the migration of neocortical interneurons. Eur J Neurosci 38:2019 2029. https://doi.org/10.1111/ejn.12225

Medina L, Legaz I, Gonzalez G, De Castro F, Rubenstein JL, Puelles L (2004) Expression of Dbx1, Neurogenin 2, Semaphorin 5A, Cadherin 8, and Emx1 distinguish ventral and lateral pallial histogenetic divisions in the developing mouse claustroamygdaloid complex. J Comp Neurol 474:504-523

Nakagawa S, Takeichi M (1998) Neural crest emigration from the neural tube depends on regulated cadherin expression. Development 125:2963-2971

Neale BM et al (2012) Patterns and rates of exonic de novo mutations in autism spectrum disorders. Nature 485:242-245. https://doi. org/10.1038/nature11011

O'Roak BJ et al (2012a) Sporadic autism exomes reveal a highly interconnected protein network of de novo mutations. Nature 485:246-250. https://doi.org/10.1038/nature10989

O'Roak BJ et al (2012b) Multiplex targeted sequencing identifies recurrently mutated genes in autism spectrum disorders. Science 338:1619-1622. https://doi.org/10.1126/science.1227764

Osterhout JA, Josten N, Yamada J, Pan F, Wu SW, Nguyen PL, Panagiotakos G, Inoue YU, Egusa SF, Volgyi B, Inoue T, Bloomfield SA, Barres BA, Berson DM, Feldheim DA, Huberman AD (2011) Cadherin-6 mediates axon-target matching in a non-image-forming visual circuit. Neuron 71:632-639. https://doi.org/10.1016/j.neuro n.2011.07.006

Oyabu A, Tashiro Y, Oyama T, Ujihara K, Ohkawara T, Ida-Eto M, Narita M (2013) Morphology of the facial motor nuclei in a rat model of autism during early development. Int J Dev Neurosci 31:138-144. https://doi.org/10.1016/j.ijdevneu.2012.12.002

Pagnamenta AT, Khan H, Walker S, Gerrelli D, Wing K, Bonaglia MC, Giorda R, Berney T, Mani E, Molteni M, Pinto D, Le Couteur A, Hallmayer J, Sutcliffe JS, Szatmari P, Paterson AD, Scherer SW, Vieland VJ, Monaco AP (2011) Rare familial 16q21 microdeletions under a linkage peak implicate cadherin 8 (CDH8) in susceptibility to autism and learning disability. J Med Genet 48:48-54. https://doi. org/10.1136/jmg.2010.079426

Pensold D, Zimmer G (2018) Single-cell transcriptomics reveals regulators of neuronal migration and maturation during brain development. J Exp Neurosci 12:1179069518760783. https://doi. org/10.1177/1179069518760783

Sawada G, Ueo H, Matsumura T, Uchi R, Ishibashi M, Mima K, Kurashige J, Takahashi Y, Akiyoshi S, Sudo T, Sugimachi K, Doki Y, Mori M, Mimori K (2013) CHD8 is an independent prognostic indicator that regulates $\mathrm{Wnt} / \beta$-catenin signaling and the cell cycle in gastric cancer. Oncol Rep 30:1137-1142. https://doi.org/10.3892/ or.2013.2597

Southwell DG, Paredes MF, Galvao RP, Jones DL, Froemke RC, Sebe JY, Alfaro-Cervello C, Tang Y, Garcia-Verdugo JM, Rubenstein JL, Baraban SC, Alvarez-Buylla A (2012) Intrinsically determined cell death of developing cortical interneurons. Nature 491:109-113. https://doi.org/10.1038/nature11523

Suzuki SC, Furue H, Koga K, Jiang N, Nohmi M, Shimazaki Y, KatohFukui Y, Yokoyama M, Yoshimura M, Takeichi M (2007) Cadherin-8 is required for the first relay synapses to receive functional inputs from primary sensory afferents for cold sensation. J Neurosci 27:3466-3476

Takeichi M (2007) The cadherin superfamily in neuronal connections and interactions. Nat Rev Neurosci 8:11-20

Tamamaki N, Yanagawa Y, Tomioka R, Miyazaki J, Obata K, Kaneko $\mathrm{T}$ (2003) Green fluorescent protein expression and colocalization with calretinin, parvalbumin, and somatostatin in the GAD67-GFP knock-in mouse. J Comp Neurol 467:60-79

Taniguchi H, Kawauchi D, Nishida K, Murakami F (2006) Classic cadherins regulate tangential migration of precerebellar neurons in the caudal hindbrain. Development 133:1923-1931 
Thomaidou D, Mione MC, Cavanagh JF, Parnavelas JG (1997) Apoptosis and its relation to the cell cycle in the developing cerebral cortex. $\mathrm{J}$ Neurosci 17:1075-1085

Treubert-Zimmermann U, Heyers D, Redies C (2002) Targeting axons to specific fiber tracts in vivo by altering cadherin expression. J Neurosci 22:7617-7626

Williams ME, Wilke SA, Daggett A, Davis E, Otto S, Ravi D, Ripley B, Bushong EA, Ellisman MH, Klein G, Ghosh A (2011) Cadherin-9 regulates synapse-specific differentiation in the developing hippocampus. Neuron 71:640-655. https://doi.org/10.1016/j.neuro n.2011.06.019

Ying G, Wu S, Hou R, Huang W, Capecchi MR, Wu Q (2009) The protocadherin gene Celsr3 is required for interneuron migration in the mouse forebrain. Mol Cell Biol 29:3045-3061. https://doi. org/10.1128/mcb.00011-09 